\title{
Correos electrónicos de autoridades públicas: En torno a una mala caracterización jurídica (Tribunal Constitucional)
}

\author{
Comentario de Fernando Muñoz León
}

Santiago, once de septiembre de dos mil doce.

VISTOS:

\section{$(\ldots)$}

CONSIDERANDO:

\section{$(\ldots)$}

\section{Precisiones PRELIMINARES}

Sexto. Que, por otra parte, esta Magistratura debe precisar, en primer lugar, que no está conociendo de oficio de este recurso. A ella le ha sido presentado un recurso de inaplicabilidad, por las personas y de acuerdo al procedimiento que el ordenamiento jurídico establece. El conflicto traído a esta sede consiste en resolver sobre sí los correos electrónicos cursados entre dos funcionarios públicos están o no protegidos por el artículo 19, $\mathrm{N}^{\text {os }} 4^{\circ}$ y $5^{\circ}$, de la Carta Fundamental. Las normas impugnadas han sido invocadas por el requerimiento. Por lo mismo, este Tribunal no tiene otra alternativa que resolver el presente conflicto, tal como lo dispone el inciso segundo del artículo $3^{\circ}$ de la ley orgánica constitucional de esta Magistratura;

SÉPtimo. Que, en segundo lugar, no se considera que por la formulación del requerimiento se cuestione la institucionalidad de la Ley $\mathrm{N}^{\circ} 20.285$, como se planteó en estrados. Este Tribunal está llamado a pronunciarse sobre la constitucionalidad de cierto precepto legal que puede ser relevante al momento de que una Corte de Apelaciones resuelva un reclamo de ilegalidad. Sin duda que la decisión impactará en la gestión pendiente. Para eso está diseñado el recurso de inaplicabilidad, para excluir o permitir la inclusión de preceptos legales dentro del abanico de normas que tiene el juez de la instancia para resolver el asunto controvertido. Esa decisión no implica cuestionar la institucionalidad. Es velar por la supremacía constitucional que el 
Tribunal Constitucional, de modo especial y a través de distintos instrumentos, como el recurso de inaplicabilidad, debe resguardar. Aquí no está en juego el rol del Consejo para la Transparencia, sino una norma del artículo $5^{\circ}$ del artículo primero de la Ley No 20.285, para un caso concreto. Porque, no está demás recordarlo, las sentencias de inaplicabilidad sólo producen efecto en el caso en que se dicten, sin perjuicio de que puedan ser consideradas como precedentes para otros casos futuros semejantes (STC 171/93, 1572/2010);

Octavo. Que, en tercer lugar, la decisión que se adopte, ha de basarse en nuestro marco constitucional. Si avanzamos o retrocedemos o permanecemos igual respecto de lo que sucede en otros países, en la materia debatida, no es algo que nos toque examinar a nosotros. Si juzgamos en base al estándar de lo que los otros países puedan considerar jurídicamente correcto, dejamos de ser un órgano encargado de velar por la supremacía de nuestra Constitución. Ésta es la que nos proporciona el parámetro de nuestro enjuiciamiento. Los marcos jurídicos de otros países pueden ilustrar (STC 1419/2009), proporcionar argumentos, transmitir experiencias, entregar metodologías de análisis, comparar los textos normativos (STC 346/2002). Como dice Zagrebelsky, el derecho constitucional extranjero es "un amigo con gran experiencia, que nos hace pensar mejor, devela energías potenciales latentes, extiende las perspectivas y enriquece las argumentaciones, poniendo bajo la luz puntos de vista quizá de otro modo ignorados. Este derecho sirve como un espejo, que permite que cada país se observe y comprenda mejor" (Zagrebelsky, Gustavo; Jueces constitucionales; en Boletín Mexicano de Derecho Comparado, Nueva serie; año XXXIX, No 117, septiembre-diciembre 2006, pp. 1135-1151).

Sin embargo, las normas constitucionales de otros países no han pasado por los procedimientos de aprobación internos; tienen, por tanto, un déficit democrático respecto a nuestro país. Además, al no estar reglada su invocación, puede existir cierta arbitrariedad en su empleo. También puede romper el carácter integrador que algunas normas constitucionales juegan en una sociedad pluralista. Asimismo, puede ser disímil o contradictorio entre sí. No obstante, hay, sin duda, un derecho constitucional común (Häberle, Peter; Derecho constitucional común europeo; en Revista de Estudios Políticos $\mathrm{N}^{\circ} 79$, enero-marzo 93, págs. 7 y siguientes) o un "constitucionalismo global" (Ferrajoli, Luigi; Más allá de la soberanía y de la ciudadanía: un constitucionalismo global; en Isonomía $\mathrm{N}^{\circ}$ 9, octubre 1998, p. 173 y siguientes). Hay normas que son universales, que tienen autoridad moral. Sin embargo, esta Magistratura no puede utilizar el derecho constitucional extranjero como parámetro para resolver un asunto sometido a su conocimiento. Como recién señalamos, sólo puede servir para ilustrar, proporcionar argumentos y transmitir experiencias, además de establecer comparaciones;

Noveno. Que, en cuarto lugar, no podemos resolver lo que nos parece óptimo, mejor o más conveniente. Una resolución en base a esas variables, está en el ámbito del legislador. Para eso, la ciudadanía elige a sus representantes: para que evalúen en base a dichas consideraciones la regulación que quieren que exista en un sector determinado. Nosotros no resolvemos en base al mérito de un asunto que nos es sometido 
a consideración. Lo hacemos en base a la contradicción entre un precepto legal y la Constitución (STC 1065/2008, 1295/2009, 1345/2009);

\section{FACTORES INTERPRETATIVOS QUE GUIARÁN LA DECISIÓN DE ESTE TRIBUNAL}

DÉcımo. Que, para resolver el presente requerimiento, queremos señalar cuatro elementos interpretativos que orientarán la decisión: que los funcionarios públicos tienen derechos constitucionales; que el derecho de acceso a la información no es un derecho absoluto; que los correos electrónicos no son necesaria e inequívocamente actos administrativos, y que la Constitución debe interpretarse a la luz del progreso tecnológico;

Los funcionarios tienen derechos constitucionales.

UNDÉcImo. Que los funcionarios públicos están sujetos a una relación estatutaria. El vínculo que une al funcionario con el Estado es una relación jurídica legal y de derecho público. Ello significa, por una parte, que encuentra su origen en la ley y no en un convenio entre la Administración y los funcionarios. Sus derechos, obligaciones, deberes, prohibiciones, están impuestos de modo general y unilateral por el ordenamiento jurídico. Por la otra, que en su establecimiento y regulación predomina el interés general por sobre el interés particular del funcionario (STC 12/1982);

Duodécimo. Que, sin embargo, ese régimen estatutario de los funcionarios se limita a regular la actividad funcionarial y no suspende los derechos que la Constitución garantiza a toda persona.

La Constitución reconoce una titularidad amplia de derechos constitucionales. El artículo 19 comienza señalando que la Constitución asegura "a todas las personas" ciertos derechos. En esa amplia titularidad, caben los funcionarios públicos.

La Constitución consagra, entonces, que los funcionarios, al igual que el resto de las personas, sean titulares de los derechos fundamentales que ella asegura.

De hecho, la Constitución se preocupa de establecer directamente algunas restricciones en el ejercicio de ciertos derechos. Así, por ejemplo, los funcionarios públicos no pueden declararse en huelga (artículo $19 \mathrm{~N}^{\circ} 16^{\circ}$ ); y las Fuerzas Armadas y Carabineros son cuerpos "esencialmente obedientes y no deliberantes" (artículo 101).

Por lo demás, la titularidad de derechos constitucionales por parte de funcionarios públicos ha sido reconocida por esta Magistratura, de modo general (STC 1990/2012) y de modo particular respecto de ciertos derechos (por ejemplo, STC 640/2005);

Decimotercero. Que dicha concepción se ve reconocida por el legislador. Por una parte, la Ley Orgánica Constitucional de Bases Generales de la Administración del Estado establece excepcionales restricciones a los derechos constitucionales de los funcionarios públicos. Por ejemplo, mediante la declaración de intereses y de patrimonio (artículos 57 y siguientes) se afecta la vida privada; a través del establecimiento de 
ciertas inhabilidades (artículo 54), se afecta la libertad de trabajo. Lo mismo se observa en la restricción al ejercicio libre de cualquier profesión, industria, comercio u oficio, pues se permite sólo si ello es conciliable con la posición en la administración, no perturba el fiel y oportuno cumplimiento de los deberes funcionarios, se desarrolla fuera de la jornada de trabajo y con recursos privados (artículo 56). Por la otra, el Estatuto General del Personal de la Administración (Ley $\mathrm{N}^{\circ}$ 18.884) o los estatutos de carácter especial para determinadas profesiones o actividades, también establecen pocas restricciones. Por ejemplo, el Estatuto Administrativo General impide realizar cualquier actividad política dentro de la Administración del Estado (artículo 84, letra h)); y obliga a los funcionarios a observar una vida social acorde con la dignidad del cargo (artículo 61, letra i)) o a proporcionar, con fidelidad y precisión, los datos que la institución le requiera relativos a situaciones personales o de familia, cuando ello sea de interés para la Administración, debiendo ésta guardar debida reserva de los mismos. Incluso personal sometido a una intensa relación especial de sujeción, como el personal de las Fuerzas Armadas, puede ejercer libremente cualquier profesión, industria, comercio u oficio, sujeto a ciertas condiciones: que ello sea conciliable con su posición en las Fuerzas Armadas, se efectúe fuera de la jornada habitual de trabajo, que no afecte el servicio y que no se contraponga con los intereses de las Fuerzas Armadas (artículo 211, D.F.L. 1/1997, Estatuto del Personal de las Fuerzas Armadas). Otro ejemplo en esta línea tiene que ver con cargos de dedicación exclusiva, que llevan aparejadas asignaciones. No obstante, dicho personal puede percibir emolumentos que provengan de la administración de su patrimonio o del desempeño de la docencia (Ley $\mathrm{N}^{\circ}$ 19.863).

Como se observa, las limitaciones tienen que ver con derechos muy específicos y están señaladas excepcional y determinadamente;

Decimocuarto. Que, por lo mismo, estas restricciones o limitaciones -que deben ser restrictivas- a los derechos de los funcionarios exigen, por de pronto, una expresa consagración normativa. Asimismo, que ellas se funden en las necesidades del servicio, o bien desarrollen o complementen preceptos constitucionales. También, que digan relación con el carácter "técnico-profesional" de la función pública. Finalmente, que dichas limitaciones deben ser precisas y determinadas;

El mandato de publicidad no es absoluto y es sólo respecto de ciertos asuntos.

Decimoquinto. Que un segundo factor interpretativo que debe dejarse establecido, es la forma en que se concibe el mandato de publicidad establecido en el artículo $8^{\circ}$ de la Constitución.

Para ello es necesario repasar lo que esta Magistratura ha señalado al respecto. En primer lugar, su propósito es garantizar un régimen republicano democrático; además, que se garantice el control del poder, obligando a las autoridades a responder a la sociedad de sus actos y dar cuenta de ellos; también, promover la responsabilidad de los funcionarios sobre la gestión pública; y, finalmente, fomentar una mayor participación de las personas en los intereses de la sociedad (STC 634/2007; 1732/2011; 1800/2011; y 1990/2012). 
En segundo lugar, dicho artículo $8^{\circ}$ no consagra un derecho de acceso a la información. Este, más bien, se encuentra reconocido implícitamente en el artículo 19 $\mathrm{N}^{\circ} 12^{\circ}$ de la Constitución (STC 634/2007 y 1990/2012). El hecho de que se encuentre en el Capítulo I de la Constitución, no lo pone por sobre el Capítulo III, que contiene el artículo 19, estableciendo el catálogo de derechos de la Carta Fundamental (STC 1990/2012).

En tercer lugar, el acceso a la información no recae sobre todo lo que hace o tienen los órganos del Estado, sino sólo sobre sus actos y resoluciones, sus fundamentos y los procedimientos que utilicen. La Constitución no habla de información (STC 1990/2012).

En cuarto lugar, dicho derecho no tiene carácter absoluto (STC 634/2007, 1732/2011 y 1800/2012). La publicidad es necesaria para el bien común, pero debe hacerse respetando los derechos que el ordenamiento establece (STC 1990/2012) y otros principios, como el principio de servicialidad del Estado (STC 1892/2011). Es lícito, en consecuencia, que el legislador, invocando o teniendo en cuenta las causales que la Constitución establece para calificar el secreto o reserva, cree excepciones a dicha publicidad (STC 1990/2012).

En quinto lugar, la Ley $\mathrm{N}^{\circ} 20.285$ es un elemento de partida para la interpretación del artículo $8^{\circ}$. Pero son las leyes las que deben interpretarse conforme a la Constitución y no ésta en base a aquéllas (STC 1990/2012). Además, el carácter público de los actos, fundamentos y procedimientos, puede lograrse a través de las modalidades que el legislador establezca, sin que exista un único mecanismo. Puede consistir en la entrega de un documento, en el acceso a ellos, en su publicación, en la puesta a disposición del público, en su difusión por distintos medios (STC 1990/2012). La Ley No 20.285 no puede considerarse como la única y exclusiva normativa que concentra todo lo referente a la publicidad ordenada por el artículo $8^{\circ}$ (STC 1990/2012; 2152/2012);

Decimosexto. Que, además, conforme a la Constitución, son públicos sólo ciertos aspectos de la actuación administrativa: los actos y resoluciones, sus fundamentos y los procedimientos que utilicen (STC 1990/2012);

Decimoséptimo. Que eso es consistente con la causal para eximir de publicidad aquellos actos, resoluciones, fundamentos o procedimientos que afecten el debido cumplimiento de las funciones de los órganos de la Administración.

Esta expresión tiene algunos ejemplos en el artículo $21, \mathrm{~N}^{\circ} 1$, del artículo primero de la Ley $\mathrm{N}^{\circ}$ 20.285. Esta causal se da cuando la publicidad requiera distraer indebidamente a los funcionarios del cumplimiento regular de sus labores; cuando se formulen requerimientos genéricos, referidos a un elevado número de actos administrativos; cuando se trate de antecedentes o deliberaciones previas a la adopción de una resolución; cuando se trate de antecedentes necesarios a defensas jurídicas y judiciales.

Dichas causales tienen que ver con que se menoscabe o impacte negativamente, interfiriendo las tareas entregadas por el ordenamiento jurídico a un órgano determinado. En definitiva, cuando la publicidad afecte la mejor toma de decisiones, porque se revela prematuramente algo o se difunde un asunto que no estaba destinado a ese propósito; 
Decimoctavo. Que esta razón es consistente con restricciones a la publicidad, tanto en el Congreso Nacional como en los tribunales colegiados.

En efecto, esta Magistratura legitimó que en la Ley Orgánica del Congreso (artículo 5 A) se hiciera un distingo respecto de la publicidad de ciertos antecedentes vinculados a la elaboración de la ley. Por una parte, las sesiones de las cámaras, los documentos y registros de las mismas, las actas de sus debates, la asistencia y las votaciones son públicas. Por la otra, no son públicos los materiales de registro de las secretarías de las comisiones $y$ de los comités parlamentarios, tales como grabaciones, apuntes $u$ otros instrumentos de apoyo a esa labor. Esta Magistratura consideró que ese precepto era constitucional; aunque le formuló una precisión: en el entendido que sólo se refiere a los insumos necesarios para que tanto las comisiones como los comités parlamentarios puedan tomar las decisiones que les correspondan en ejercicio de sus funciones (STC 1602/2010).

Lo mismo se observa en los tribunales colegiados. Éstos celebran sus acuerdos privadamente (artículo 81, Código Orgánico de Tribunales);

Decimonoveno. Que es un hecho que impone la realidad, que la naturaleza humana tiende a ser más prudente y recatada si sabe que sus actos serán conocidos. En general, esto puede ser positivo. Sin embargo, ello puede afectar la deliberación técnica, restando espontaneidad, franqueza, dureza, en los diálogos, consejos o asesorías dentro de los órganos llamados a tomar decisiones. Estos deben tener un margen para explorar alternativas con libertad, sin tener que saber que sus opiniones se harán públicas. Si la Administración debe obtener resultados, cumplir el mandato de actuar con eficacia (artículo 11, Ley $\mathrm{N}^{\circ} 18.575$ ), debe considerarse y respetarse un espacio para que la asesoría y el intercambio de opiniones sean los más amplios posibles. Y eso se obtiene con ciertos márgenes de reserva de esos diálogos.

Por lo demás, no todo lo que sucede en la Administración, ni aun con el artículo $8^{\circ}$ constitucional y la Ley $\mathrm{N}^{\circ} 20.285$, puede ser público, pues hay conversaciones, reuniones, llamados telefónicos, diálogos, órdenes verbales, entre los funcionarios, de los cuales no se lleva registro de ningún tipo. Y, por lo mismo, nunca serán públicos.

Lo que se incorpora a un expediente administrativo son, como dice la Ley $\mathrm{N}^{\circ} 19.880$, los documentos, las actuaciones, las resoluciones, los informes, las notificaciones y comunicaciones, los escritos, presentados por los órganos de la Administración, por los interesados, o por terceros (artículo 18). Todo ello permite un intercambio de información entre todos los involucrados en las decisiones públicas, que facilite que se adopte la mejor decisión posible. Entre más información tenga la autoridad llamada a resolver, más posibilidades tendrá de tomar una decisión adecuada al problema que pretende atender;

Vigésimo. Que el carácter reservado o secreto de un asunto no es algo en sí mismo perverso, reprochable o susceptible de sospecha. La Constitución contempla la posibilidad de que la ley directamente o la Administración, sobre la base de ciertas causales legales específicas, declare algo como secreto o reservado. Esto no va contra la Constitución.

El carácter secreto o reservado de un acto, de un documento, de un fundamento, no es inmunidad ni ausencia de control. Existen otras formas de fiscalización, como es el 
procedimiento administrativo, los recursos administrativos, el ejercicio de las potestades de la Contraloría General de la República, etc. Todas esas formas permiten un escrutinio de lo que la Administración hace o deja de hacer y permiten que los ciudadanos puedan realizar una crítica fundada de las decisiones de la autoridad.

Además, el carácter secreto o reservado de un acto puede generar un espacio para cautelar otros bienes jurídicos que la Constitución estima tan relevantes como la publicidad. En el lenguaje de la Constitución, los derechos de las personas, la seguridad de la Nación, el interés nacional, o el debido cumplimiento de las funciones de los órganos, están a este nivel. Por lo mismo, deben ser respetados y considerados.

Los órganos de la Administración del Estado tienen como labor primordial promover el bien común, atendiendo las necesidades públicas en forma continua o permanente y fomentando el desarrollo del país (artículo $3^{\circ}$ de la Ley $\mathrm{N}^{\circ} 18.575$ ), lo cual debe llevar a cabo con pleno respeto a los derechos y garantías que la Constitución establece (artículo $1^{\circ}$ de la Constitución Política de la República). En este sentido, éstos deben actuar con publicidad, pero ésta no es la única finalidad de la Administración. Para la labor que se le encarga, la Administración debe observar una serie de principios. Entre éstos están la publicidad, la participación, pero también la eficiencia, la eficacia de su actuación.

La transparencia es un bien de primera importancia para la Constitución. Sin embargo, no es el único, pues la Administración debe crear las condiciones sociales que permitan que las personas puedan realizarse espiritual y materialmente (artículo $1^{\circ}$ de la Constitución). Esa inmensa labor se debe facilitar.

Eso explica la causal de afectar el debido cumplimiento de las funciones de dichos órganos que el artículo $8^{\circ}$ establece como una excepción a la publicidad;

Los correos electrónicos no son necesariamente actos administrativos.

VIGÉSIMO PRIMERO. Que un tercer factor de interpretación es que los correos electrónicos no necesariamente son actos administrativos.

En efecto, el correo electrónico es, en primer lugar, una forma de comunicación, pues por este medio se transmiten mensajes de un emisor a uno o varios receptores. Esta comunicación exige un soporte técnico, pues requiere la intervención de aparatos, de redes o infraestructuras, de operadores de estas, de programas informáticos, de protocolos de transferencia en la Internet. Hay de por medio un proceso de transmisión del mensaje o contenido.

En segundo lugar, el correo es una comunicación digitalizada, pues el mensaje es convertido a datos o números en base binaria (ceros y unos), que conforman los bits (binary digits).

En tercer lugar, el correo electrónico se transmite por un canal cerrado, en el sentido de que a él no pueden acceder terceros. En eso se distingue de la transmisión de radio o televisión. Recordemos que las concesiones radiales se denominan servicios de telecomunicaciones de libre recepción, porque las transmisiones que estas emiten están destinadas a la recepción libre y directa por el público en general (artículo $3^{\circ}$, letra a), de la Ley $\mathrm{N}^{\circ}$ 18.168). Y las concesiones de televisión se denominan concesiones de servicio de radiodifusión televisiva de libre recepción (artículo 15, Ley $\mathrm{N}^{\circ}$ 18.838). 
Finalmente, el correo electrónico es una forma de comunicación que tiene ciertas características. Por de pronto, la virtualidad. El emisor y el receptor no están físicamente presentes. En este sentido, es una comunicación a distancia. Por eso se habla de ciberespacio para designar la carretera por donde viaja la información. Enseguida, se encuentra la instantaneidad, la que consiste en que el mensaje se transmite a alta velocidad, de modo que puede ser recepcionado casi en tiempo real. A continuación, está la multidireccionalidad, dada porque pueden participar varios emisores y receptores, y cambiar en esos roles. Asimismo, se encuentra el carácter multimedial, pues a través de él se pueden transmitir datos, imágenes, sonidos. Finalmente, está la ubicuidad. Esta consiste en que el correo puede ser abierto por el destinatario en cualquier lugar en que se den las condiciones técnicas para ello (Lambea Rueda, Ana; El correo electrónico; en Revista de Derecho Privado, Madrid, diciembre 2002, pp. 936-963; y Rodríguez S., Eduardo; El correo electrónico; en Revista Chilena de Derecho Informático, $\mathrm{N}^{\circ} 3$ );

Vigésimo segundo. Que el uso del correo electrónico en la Administración resulta particularmente atractivo por su interactividad, conectividad, informalidad e instantaneidad. Su uso acelera enormemente el flujo de información necesaria para que aquella pueda tomar decisiones, acortando distancias, permitiendo que muchas personas puedan interactuar. Además, no tiene la ritualidad de las otras formas de comunicación formales e internas de la Administración, como el oficio y la circular, que requieren firma, numeración, despacho formal. Ello facilita e incentiva su uso, pues permite un intercambio franco y directo de opiniones e información.

El uso de estas nuevas tecnologías ha llevado a que se hable de gobierno electrónico. Este es el uso de las tecnologías de información y comunicaciones que realizan los órganos de la Administración para mejorar los servicios e información ofrecidos a los ciudadanos, aumentar la eficiencia y eficacia en la gestión pública.

El gobierno electrónico, en consecuencia, forma parte del proceso de reforma y modernización del Estado. De este son parte proyectos transversales, como la intranet del Estado, Chilecompra, el Sistema de Información para la Gestión Financiera del Estado, la Ventanilla Única, el Sistema Nacional de Información Territorial; y proyectos sectoriales, como la factura electrónica, la licencia médica electrónica, etc.

En la actualidad, prácticamente todos los órganos de la Administración tienen páginas web, donde las personas pueden consultar, informarse, realizar trámites, formular consultas. Incluso hay regulaciones administrativas de las comunicaciones electrónicas de las personas a los órganos de la Administración (D.S. No 77, 2004, Minsegpres);

Vigésimo tercero. Que, en ese marco, la Ley de Bases de los Procedimientos Administrativos (Ley $\mathrm{N}^{\circ} 19.880$ ) permite que los procedimientos administrativos y los actos administrativos se expresen por escrito o por medios electrónicos (artículos $5^{\circ}, 18$ y 19). Sin embargo, los actos administrativos son decisiones formales (artículo $3^{\circ}$, inciso segundo). Dichas formalidades deben ser al menos aquellas indispensables para dejar constancia indubitada de lo actuado y evitar perjuicios a los particulares (artículo $13^{\circ}$ ); 
Vigésimo cuarto. Que, en este sentido, es importante considerar la Ley N N $^{\circ}$. 799 , que regula los documentos electrónicos y la firma electrónica. Esta ley da definiciones relevantes de considerar. Por una parte, define documento electrónico como toda representación de un hecho, imagen o idea que sea creada, enviada, comunicada o recibida por medios electrónicos y almacenada de un modo idóneo para permitir su uso posterior (artículo $2^{\circ}$, letra d). Por la otra, define firma electrónica como cualquier sonido, símbolo o proceso electrónico que permita al receptor de un documento electrónico identificar al menos formalmente a su autor (artículo $2^{\circ}$, letra $\mathrm{f}$ ).

Sin embargo, para que un documento electrónico sea válido, es necesario que se cumpla un requisito: que sea suscrito por firma electrónica. Así lo dispone su artículo $7^{\circ}$ : los actos, contratos y documentos de los órganos del Estado, suscritos mediante firma electrónica, serán válidos de la misma manera y producirán los mismos efectos que los expedidos por escrito y en soporte de papel (artículo $7^{\circ}$ );

VIGÉsimo QUINTO. Que, de este modo, para que estemos en presencia de un acto administrativo producido por medios electrónicos, no basta el solo hecho de que un documento sea electrónico. Es necesaria, además, la existencia de dicha firma. Dicha firma debe ser certificada, mediante firma electrónica simple o avanzada (artículos $7^{\circ}$ y siguientes). Ello permite garantizar su autenticidad, su integridad, su seguridad, su confidencialidad. Dicha exigencia materializa la equivalencia funcional de ambos sistemas;

Vigésimo sexto. Que, por otra parte, la Ley de Procedimiento Administrativo reconoce, en lo que aquí interesa, tres tipos de actos administrativos. En primer lugar, están aquellos que deciden. En este sentido, esta ley regula la resolución que pone término a un procedimiento (artículo 41). En segundo lugar, se encuentran los actos de constancia. Estos no resuelven nada, sino que se limitan a certificar la existencia de un hecho o de un acto (artículo $3^{\circ}$, inciso sexto). Finalmente, se encuentran los actos de juicio o de dictamen. Estos son aquellos en que un órgano administrativo expresa el punto de vista correspondiente a sus competencias respectivas (artículo 38). Estos dictámenes pueden ser facultativos y, por tanto, pueden o no requerirse por el órgano llamado a resolver; o pueden ser obligatorios. En este caso, el órgano que resuelve debe solicitarlo, generándose un vicio en el procedimiento si se omite requerirlo (artículos 37 y 38). Ahora, estos informes deben ser analizados al momento que la Administración resuelva, apreciándose en conciencia (artículo 35);

Vigésımo séptimo. Que lo anterior tiene importancia, porque para que un informe o dictamen se entienda comprendido dentro del derecho de acceso a la información, debe cumplir dos condiciones.

En primer lugar, debe ser genuinamente un informe. Los informes se dictan en el marco de un procedimiento al cual acceden. La autoridad llamada a resolver debe pedirlos, por ser obligatorios, o puede pedirlos, por ser facultativos (artículos 37 y 38, Ley $\mathrm{N}^{\circ}$ 19.880). La decisión se materializa en un acto trámite (artículo 24) y de ella se 
deja constancia en el expediente (artículo 18). La autoridad requerida para proporcionarlos, debe evacuarlos en un plazo que la ley establece (artículo 24). No obstante, su retraso no detiene el procedimiento (artículo 38). Una vez evacuado, se producen dos efectos. De un lado, deben incorporarse al expediente administrativo (artículo 18). Por esa incorporación, todos los interesados pueden acceder a él, por derecho de estos (artículo 17, letra d)). Por el otro, deben ser ponderados en la resolución final, pues para eso se emiten (artículo 35). Esto es, para servir de base a la decisión. Los informes son ejercicio de competencias (artículos $3^{\circ}$ y 38 ).

Distintas de los informes son las opiniones o puntos de vista que una autoridad puede pedir a otra o a un funcionario o a un asesor. Estas no se encuentran regladas. En tal sentido, no son ejercicio de competencias, no se registran y no producen efectos jurídicos.

En segundo lugar, debe tratarse de un acto propiamente tal o de un documento que sirva de complemento directo o complemento esencial del acto administrativo respectivo, tal como lo señala el inciso primero del artículo $5^{\circ}$ del artículo primero de la Ley $\mathrm{N}^{\circ} 20.285$.

A este respecto, el reglamento de la Ley $\mathrm{N}^{\circ} 20.285$ (D.S. $\mathrm{N}^{\circ} 13,2009$, Minsegpres) señala que, de un lado, documento es todo escrito, correspondencia, memorándum, plano, mapa, dibujo, diagrama, documento gráfico, fotografía, microforma, grabación sonora, video, dispositivo susceptible de ser leído mediante la utilización de sistemas mecánicos, electrónicos o computacionales $y$, en general, todo soporte material que contenga información, cualquiera sea su forma física o características, así como las copias de aquellos. Del otro, que un documento puede ser complemento directo o complemento esencial. Es complemento directo si cumple dos condiciones. Por una parte, se vincula necesariamente con el acto y, por la otra, si dicho acto se dictó precisa e inequívocamente sobre esa base (artículo $3^{\circ}$, letra g). Un documento es complemento esencial si ha sido indispensable para la elaboración y dictación del acto y es inseparable del mismo (artículo $3^{\circ}$, letra h).

De este modo, si un documento no se encuentra en alguno de estos supuestos, no está dentro de aquellos que pueden ser conocidos vía derecho de acceso a la información pública;

La Constitución debe interpretarse a la luz del progreso tecnológico.

Vigésimo octavo. Que, finalmente, no se nos escapa que debemos resolver un asunto donde están involucradas nuevas tecnologías, con normas constitucionales que no las tuvieron en cuenta, porque no existían cuando fueron formuladas. Por lo mismo, debemos realizar un proceso hermenéutico para interpretar dichos textos en el contexto de la sociedad tecnológica. Ello implica incorporar las nuevas tecnologías a las normas constitucionales y considerar que nuestra Constitución recoge no solo la libertad de prensa común y corriente, sino también la libertad de prensa electrónica, la libertad de reunión electrónica, la inviolabilidad de las comunicaciones electrónicas. Tenemos que ser jueces en la sociedad tecnológica (Frosini, Tommaso; Nuevas tecnologías y constitucionalismo; Revista de Estudios Políticos (Nueva Época), No 124, abril-junio 2004, pp. 129-147).

Más todavía si hoy se habla de democracia electrónica, para aludir al voto electrónico, a la consulta y participación en línea de los ciudadanos, mediante peticiones y foros. Ello plantea el desafío de reducir el analfabetismo electrónico y garantizar el acceso a 
las redes (Petrauskas, Rimantas; Los principios y la implementación de la democracia electrónica, en Galindo, Fernando; Gobierno, derecho y tecnología: las actividades de los poderes públicos; Editorial Thomson Civitas; Madrid, 2006, pp. 85-113).

En este sentido, los correos electrónicos permiten acceder a la autoridad directamente, sin intermediarios. También permiten el flujo de información para que los encargados de decidir se inclinen por las mejores opciones posibles. Asimismo, aceleran la toma de decisiones.

Pero es un hecho que los correos electrónicos tienen pocas regulaciones, y no hay consenso sobre si las debe haber. Eso obliga a ser prudente en el examen de los conflictos que su uso plantea;

\section{$(\ldots)$}

\section{El INCISO SEGUNDO DEL ARTículo QUiNTO DE LA LEY N 20.285 EXCEDE LO PREVISTO EN LA CONSTITUCIÓN}

\section{La controversia}

Quincuagésimo tercero. Que la Subsecretaría del Interior sostiene también que el inciso segundo del artículo $5^{\circ}$ del artículo primero de la Ley $\mathrm{N}^{\circ} 20.285$ excede lo previsto en el artículo $8^{\circ}$ de la Constitución. Mientras este solo habla de que son públicos los actos y resoluciones, sus fundamentos y los procedimientos que utilicen, el precepto incorpora dos nuevas categorías: la información elaborada con presupuesto público y toda otra información que obre en poder de los órganos de la administración;

QuinCUAGÉSIMO CUARTO. Que la doctrina también ha señalado que la información pública a la que se tiene acceso es de dos tipos. Una circunscrita a aquella que ha sido elaborada con presupuesto público; y otra más amplia, consistente en toda información que detenta la Administración o que esté en manos de ella (Camacho Cépeda, Gladys; Algunas precisiones sobre el concepto de información pública; en Letelier, Raúl, y Rajevic, Enrique; Transparencia en la administración pública; Editorial Abeledo Perrot, Santiago, 2010, p. 52);

Quincuagésimo Quinto. Que el Consejo para la Transparencia ha reconocido esta situación. En la decisión de amparo C1101-11 se sostiene que el legislador ha extendido la publicidad de la información más allá del tenor del artículo $8^{\circ}$ de la Constitución. El fundamento para esa ampliación lo encuentra el Consejo en que el derecho de acceso a la información se encuentra en la libertad de buscar, recibir y difundir informaciones;

Quincuagésimo sexto. Que, como se observa, no se discute el que la Ley $\mathrm{N}^{0} 20.285$, específicamente el precepto impugnado, fue más allá de lo establecido por la Constitución en el artículo $8^{\circ}$. La discusión es si esto es legítimo o no; 


\section{Un criterio de análisis}

Quincuagésimo séptimo. Que, para responder a esta interrogante, debemos considerar que el carácter limitado de la información que debe ser pública en virtud de la disposición constitucional del inciso segundo del artículo $8^{\circ}$, también fluye de una interpretación sistemática de la Constitución. En efecto y tal como se ha expuesto en la primera parte de esta decisión, la aplicación del principio de publicidad contemplado en la Constitución tiene efectos potencialmente lesivos respecto de otros intereses protegidos por la Carta Fundamental. No resulta admisible considerar que casos semejantes deban ser decididos en favor de uno de los intereses en conflicto, como ocurriría de considerarse que toda información en poder de los órganos del Estado tiene el carácter de pública. Es necesario, entonces, buscar una solución que permita garantizar el contenido fundamental de todas las disposiciones involucradas;

La manera en que el precepto impugnado excede el inciso segundo del artículo $8^{\circ}$ de la Constitución.

Quincuagésimo octavo. Que, entonces, partamos por señalar que la Ley $\mathrm{N}^{\circ} 20.285$ introduce el concepto de información. Esta expresión, como ya lo señaló esta Magistratura (STC 1990/2012), no la usa la Constitución. En cambio, la Ley $\mathrm{N}^{\circ} 20.285$ la utiliza en abundancia, desde el título de la ley misma (Sobre acceso a la información pública) hasta en una serie de disposiciones. Baste señalar que el derecho de acceso es definido como solicitar y recibir información (artículo 10, inciso primero);

Quincuagésimo noveno. Que hay dos maneras de entender la información en la Ley $\mathrm{N}^{\circ}$ 20.285. Por una parte, es la contenida en los actos, resoluciones y procedimientos (artículos $4^{\circ}, 10$, inciso segundo, 13, 14, 19, 20, 22, 23 y 26). Por la otra, es algo distinto a lo anterior y más amplio (artículos $5^{\circ}, 10$, inciso segundo, 11, letras a), b), c), d), e) y g), 12, letra b), 16 y 17);

Sexagésimo. Que mientras la Constitución habla de actos y resoluciones, el artículo impugnado habla de dos tipos de información. En primer lugar, la elaborada con presupuesto público. Con eso se permite el acceso no solo a actos y resoluciones, a fundamentos o documentos vinculados a éstos, o a los procedimientos en que se dictaron, sino también a cualquier registro, de cualquier tipo, que haya sido financiado con dineros públicos. La norma exige tres requisitos para configurar la hipótesis que regula. El primero es que se trate de información. Esta expresión es comprensiva de documentos, archivos, folletos, datos que estén registrados. El segundo requisito es que la información haya sido elaborada por la Administración. Es decir, que haya sido hecha, que sea producto de un trabajo que la origine. El tercer requisito es que esa elaboración sea financiada con el presupuesto de la Nación.

En segundo lugar, el precepto habla de información que obre en poder de los órganos de la administración. Se trata, en consecuencia, de información que debe cumplir las siguientes condiciones. Desde luego, no tiene que ser hecha por la Administración, sino 
por otras entidades, privadas, internacionales, etc. Da lo mismo su procedencia. De lo contrario estaríamos en la información anterior. Enseguida, esa información tiene que estar en poder de los órganos de la Administración. Es decir, que esté bajo su cuidado, depósito o disposición;

SeXAGÉsimo Primero. Que, entonces, el precepto impugnado amplía la información a que se tiene acceso, porque la separa completamente de si se trata de actos, resoluciones, fundamentos de éstos, o documentos que consten en un procedimiento administrativo.

Resulta difícil imaginarse una información que no esté comprendida en alguna de las dos categorías que el precepto establece. Porque la Administración o produce información o la posee a algún título.

El punto es que toda ella sería pública, independientemente de si tiene o no relación con el comportamiento o las funciones del órgano de la administración;

SeXagésimo SEgundo. Que la pregunta que nos debemos formular es si eso es lo que quiso el legislador cuando elaboró la Ley $\mathrm{N}^{\circ} 20.285$.

Existe abundante información en la historia legislativa de la Ley $\mathrm{N}^{0} 20.285$ que apunta en el sentido contrario. Lo que se buscó, por una parte, fue reproducir lo que establecía la Constitución. Por la otra, no innovar en los conceptos de acto administrativo que definía la Ley $\mathrm{N}^{\circ}$ 19.880; consignándose expresamente que las deliberaciones no se consideraban actos administrativos (Historia de la Ley $\mathrm{N}^{\circ} 20.285$, Biblioteca del Congreso Nacional, p. 117 y siguientes);

Sexagésimo tercero. Que, además, si el artículo $8^{\circ}$ hubiera querido hacer pública toda la información que produzca o esté en poder de la Administración, no hubiera utilizado las expresiones "acto", "resolución”, "fundamentos” y "procedimientos”. El uso de estas expresiones fue para enumerar aquello que se quería hacer público. El carácter taxativo se refleja en la forma clásica de listar que tienen las normas. El inciso segundo del artículo $8^{\circ}$ de la Constitución comienza señalando: son públicos ...;

Sexagésimo cuarto. Que el artículo $8^{\circ}$ de la Constitución razona sobre la base de decisiones. Por eso habla de actos y resoluciones. Y de lo que accede a estas: sus fundamentos y los procedimientos que utilicen. Por eso, el mismo artículo $5^{\circ}$, inciso primero, de la ley, cuando se refiere a los documentos no habla de cualquiera, sino de aquellos que sirven de sustento o complemento directo y esencial a tales actos y resoluciones.

En cambio, información elaborada con presupuesto público o información que obre en poder de los órganos de la Administración, no necesariamente tiene que ver con eso;

SeXagésimo QUiNTo. Que tampoco puede sostenerse que los correos electrónicos que estén al margen de un procedimiento y sobre los que se discute en la presente gestión, estén insertos en alguna de las categorías que emplea el artículo $8^{\circ}$ de la Constitución.

Por de pronto, no caben dentro de la expresión acto o resolución, por las razones que analizamos en el capítulo anterior. 
Enseguida, tampoco se encuentran dentro de la expresión fundamentos que utiliza el artículo $8^{\circ}$ de la Constitución. Fundamento de un acto es aquello en que se basa; la razón principal o el motivo para decidir en un sentido determinado. Son los documentos, los testimonios, las observaciones, los informes. Estos son los datos que la autoridad debe tener en cuenta al momento de resolver (artículos 17 y 18, Ley No 19.880), apreciándose en conciencia (artículo 35 de la misma ley). La resolución que pone término a un procedimiento administrativo, debe ser fundada (artículo 41). Pero para ello es esencial que estén en un expediente, es decir, que sean parte de un procedimiento administrativo. El dato externo no puede ser ni controvertido ni ponderado.

Además, no se ha proporcionado a esta Magistratura ningún antecedente que genere siquiera indicios para pensar que existe una conexión sustantiva o directa o esencial entre los correos y la rendición de cuentas a que se refieren los documentos que ya se entregaron por la Subsecretaría del Interior;

Sexagésimo Sexto. Que este Tribunal considera, en consecuencia, que efectivamente el inciso segundo del artículo $5^{\circ}$, impugnado en estos autos, excede, en su aplicación a la gestión pendiente de autos, lo dispuesto en la Carta Fundamental.

La relevancia para el caso concreto de lo anterior es que se ha utilizado este precepto para incluir a los correos electrónicos en información que elabora la Administración.

Ello nos parece que pugna con la Carta Fundamental, pues excede lo previsto en ella, va más allá de lo que el constituyente estimó debe publicitarse.

Y TENIENDO PRESENTE lo prescrito en los artículos $1^{\circ}, 5^{\circ}, 6^{\circ}, 7^{\circ}, 8^{\circ}$ y $19 \mathrm{~N}^{\circ} 5^{\circ}$ de la Constitución Política de la República; y artículos 30 y 31 de la Ley No 17.997, Orgánica Constitucional de este Tribunal,

\section{SE RESUELVE:}

$1^{\circ}$ Que se acoge el requerimiento deducido a fojas 1 , declarándose la inaplicabilidad del inciso segundo del artículo $5^{\circ}$ de la Ley $\mathrm{N}^{\circ} 20.285$, en la parte que dispone que es pública "toda otra información que obre en poder de los órganos de la Administración, cualquiera sea su formato, soporte, fecha de creación, origen, clasificación o procesamiento".

$2^{\circ}$ Que se deja sin efecto la suspensión dispuesta a fojas 125 , debiendo oficiarse al efecto.

Acordada con el voto en contra de los Ministros señores Francisco Fernández Fredes, José Antonio Viera-Gallo Quesney y Gonzalo García Pino, quienes estuvieron por rechazar el requerimiento, por las siguientes consideraciones:

\section{$(\ldots)$}

15.- Que en el caso sub lite se plantea una eventual colisión entre el derecho al respeto de la vida privada del artículo $19 \mathrm{~N}^{\circ} 4$ y el acceso a la información pública. Este último derecho se funda en el artículo $19 \mathrm{~N}^{\circ} 12$ de la Constitución, siendo que este 
Tribunal reconoció la existencia de un derecho de acceso a la información pública que emanaría de este último precepto constitucional (STC 634-2007) y del artículo $4^{\circ}$ de la Constitución, en virtud del cual Chile es una República democrática y sus decisiones son, evidentemente, res publica. El ejercicio de esta libertad se ve reafirmado por el bien jurídico de la transparencia, base de la institucionalidad, establecido en el inciso segundo del artículo $8^{\circ}$ que establece como regla general la publicidad de los actos y resoluciones de los órganos del Estado, así como sus fundamentos y los procedimientos que utilicen, salvo las excepciones señaladas en el mismo precepto;

\section{(...)}

\section{El JUICIO DE RAZONABILIDAD}

20.- Que el juicio de razonabilidad admite diversas variables. Sin embargo, en el caso concreto, cualquiera de los conceptos que se utilice -razonabilidad como concepto subsidiario de la estricta racionalidad (STC roles $\mathrm{N}^{\text {os }} 282,465,467,788,1452$ y 1615, entre otras) o razonabilidad como interdicción de la arbitrariedad (STC roles $\mathrm{N}^{\text {os }} 1133$, $1217,1234,1307,1332,1418$ y 1580, entre otras- se cumple en la especie. Es razonable la norma del artículo $5^{\circ}$, inciso segundo, de la Ley $\mathrm{N}^{\circ} 20.285$, cuestionada en autos, porque está vinculada al cumplimiento de objetivos o finalidades constitucionales y legales legítimas, según lo prescribe el artículo 32 de la Ley $\mathrm{N}^{\circ}$ 20.285;

21.- Que en el caso sub lite es preciso tener en cuenta que la legitimidad de la intervención sobre los derechos supuestamente afectados, supone describir las razones admisibles para intervenir en función de las exigencias de una sociedad democrática, esto es, que se trate de límites previstos por la Constitución o el legislador, según ya lo vimos, y que se deriven de la reivindicación de los derechos de los demás, por la seguridad de todos y por las justas exigencias del bien común, en una sociedad democrática (artículo 32.2 de la Convención Americana de Derechos Humanos en relación con el artículo $5^{\circ}$, inciso segundo, de la Constitución);

22.- Que, en tal sentido, la aplicación del artículo $5^{\circ}$, inciso segundo, satisface plenamente el juicio de razonabilidad a la luz de tales exigencias, dada la dimensión pública de la información solicitada;

23.-Que la solicitud recae en un asunto de evidente interés público. El artículo $8^{\circ}$ constitucional ratifica la naturaleza del planteamiento del Alcalde de Melipilla, quien, ejerciendo el derecho contemplado en el artículo 10 de la Ley $\mathrm{N}^{\circ} 20.285$, demanda de la Subsecretaría del Interior una serie de respuestas relativas a la inversión y reembolso de fondos públicos relacionados con la mitigación de los efectos del terremoto del 27 de febrero de 2010 en su comuna. La propia respuesta de la Subsecretaría del Interior, casi integralmente positiva (fs. 3 a 5), revela que existe un reconocimiento del carácter público del asunto planteado, sin especificar, inicialmente, si lo protegido por la reserva o secreto era la reivindicación de un derecho fundamental, como el respeto a la vida privada, o el ejercicio de la facultad de decidir, de conformidad con el privilegio deliberativo; 
24.-Que los procedimientos extraordinarios que se usan cuando ocurre una emergencia, exigen flexibilidad inicial para enfrentarla y traen consigo el reforzamiento de los controles posteriores, tanto de la Contraloría como de los ciudadanos mediante el acceso a la información pública. Este proceso constitucional tiene como telón de fondo el terremoto más devastador de los últimos 50 años y el cuarto de mayor magnitud en la historia de la humanidad. Este sismo y posterior maremoto afectó a seis regiones del país, implicó decretar el único estado de excepción constitucional de catástrofe dictado desde 1990 en tres regiones; se aplicó en todas las regiones afectadas la Ley $\mathrm{N}^{\circ} 16.282$, de 1965, conocida como la Ley de Sismos, y se crearon programas públicos de emergencia para mitigar, recuperar y rehabilitar edificaciones públicas y privadas. Esos programas - para actuar con eficiencia, eficacia y oportunidad- fueron eximidos de algunos requisitos legales habituales, por ejemplo en lo referente a procesos de licitación, y permitieron aplicar mecanismos excepcionales de adquisición y reparto directo de materiales;

25.- Que la solicitud del Alcalde de Melipilla abarca la información contenida en los correos electrónicos sobre cuatro asuntos específicos: los fondos entregados y transferidos por el Ministerio del Interior a la Gobernación Provincial aludida. Segundo, casillas electrónicas de las personas indicadas, más el funcionario designado por el Ministerio del Interior como contraparte de la Gobernación Provincial de Melipilla. Tercero, las rendiciones de gastos efectuados por dicha Gobernación Provincial al Ministerio del Interior, en relación al uso de esos fondos. Y, cuarto, las eventuales órdenes de devolución que hiciera dicho Ministerio a la Gobernación Provincial respecto de los mismos fondos;

26.- Que el Ministerio del Interior autorizó expresamente el uso de correos electrónicos como procedimiento excepcional de operación, regulando dicho uso para la emergencia mediante el Decreto Supremo No 355, de 29 de marzo de 2010, a cuyo efecto creó el Programa "Manos a la Obra", que permitía retribuir, entre otros, los gastos de la Municipalidad de Melipilla erogados para mitigar los daños del terremoto en su comuna. En él se autorizan los pedidos que la Municipalidad debe hacer a cada proveedor mediante:

vía telefónica, respaldado por el correspondiente correo electrónico al Ejecutivo de Cuenta que deberá ser remitido en un plazo no superior a 3 horas de efectuado el requerimiento telefónico. (...) En el evento de existir alguna discrepancia entre lo solicitado por vía telefónica y correo electrónico, primará esta última información" (cláusula tercera, letra c), del acuerdo). Para el despacho y entrega de materiales se rige el plazo por "el correo electrónico que contiene el pedido (cláusula tercera, letra e)).

Con ello, el decreto estableció como procedimiento el uso del correo electrónico para las comunicaciones entre los proveedores y la Municipalidad respectiva y para establecer la certidumbre entre pedidos por la vía telefónica y su respaldo por correo electrónico y no hace sino cumplir con lo dispuesto en el artículo 19 de la Ley de Procedimientos Administrativos, que autoriza la utilización de medios electrónicos.

Asimismo, el Informe Final No 141/2010 de Auditoría a la Subsecretaría del Interior, realizado por la Contraloría General de la República el $1^{\circ}$ de marzo de 2011, acredita que hubo rendiciones de cuentas realizadas mediante correos electrónicos; 
27.- Que, finalmente, la regla general es que todo lo que se refiera a gasto fiscal sea público. Para ello, se dispone en la Constitución de reglas especiales de aprobación del Presupuesto (artículo 67), de control de los decretos supremos que autorizan el gasto (artículo 99) por parte de la Contraloría, hasta su pago específico por la Tesorería General de la República, previa refrendación presupuestaria expedida por autoridad competente (artículo 100). Por ende, las solicitudes de acceso a la información referidas al gasto público y su destino definitivo en relación con compromisos previos, cumplen con la regla de referirse a un asunto nítidamente público;

28.-Que, en general, el acceso a la información pública no requiere invocar razones para fundar la petición. Sin embargo, a efectos del caso concreto materia de autos, las causas que motivan la solicitud permiten fijar una relación de prevalencia condicionada entre los derechos que se presentan como si fueran antinómicos. En este caso se solicita que se den a conocer determinados correos electrónicos porque no había decisión pública refrendada en un decreto ni las autoridades aludidas expresaban las razones de la decisión adoptada;

29.- Que, por tanto, el juicio de razonabilidad de la intervención que podría afectar los derechos de la parte requirente, específicamente de dos autoridades públicas, se encuentra plenamente justificado;

\section{El JUICIO DE PROPORCIONALIDAD}

30.- Que corresponde ahora realizar el juicio de proporcionalidad invocado en el requerimiento y reiterado por la requirente en la audiencia de la vista de la causa;

31.- Que el juicio de adecuación o idoneidad es el punto de partida de un examen sobre la proporcionalidad de la injerencia. La autorización del CPLT de la revisión de los correos electrónicos solicitados ¿es un mecanismo adecuado para satisfacer la necesidad de información invocada por el Alcalde de Melipilla a fin de poder controlar el gasto público y permitir la rendición de cuentas por parte de autoridades? Tal como lo estipuló el Decreto 355, de 29 de marzo de 2010, por parte de las dos autoridades vinculadas a la materia: el Subsecretario del Interior y la Gobernadora de Melipilla, ello es así. Asimismo, la solicitud abarca también los correos electrónicos del funcionario designado por el Ministerio del Interior como contraparte de la Gobernación Provincial de Melipilla. Esta medida que afecta a un funcionario innominado pero existente, es igualmente idónea para conocer la ejecución del programa y el destino final de los recursos. Llama la atención que no se reivindique el derecho al respeto a la vida privada de este funcionario, debilitando así la argumentación de la requirente. Resulta indubitado que el acceso a los correos electrónicos mencionados es una medida idónea para obtener el resultado buscado;

32.- Que, en cuanto al juicio de necesidad de la medida, ¿hay otros medios alternativos para obtener la información sobre los recursos públicos pendientes para Melipilla? Tratándose de un asunto en donde las peticiones de recursos, la asignación de los mismos y las rendiciones de cuentas del Programa Manos a la Obra se realizaron mediante 
correos electrónicos, según quedó acreditado por el Informe Final de la Contraloría del $1^{\circ}$ de marzo de 2011, el Alcalde de Melipilla opta por pedir el acceso a esos correos y, frente a la negativa, recurre ante el CPLT, conforme lo establece la Ley $\mathrm{N}^{\circ}$ 20.285. Por tanto, resulta cumplido el juicio de necesidad, puesto que ésa es la vía fijada por la ley para obtener la información, recordando que la propia autoridad validó la información mediante correos electrónicos para la aplicación del Programa Manos a la Obra;

33.- Que el juicio de proporcionalidad en un sentido estricto trata de identificar las ventajas que se obtendrían con la injerencia sobre el derecho al respeto de la vida privada, test de daño, en relación con los beneficios que se producirían con el conocimiento público de la información requerida, test de interés público.

El test de proporcionalidad en sentido estricto se satisface por las siguientes razones:

a.- Porque la solicitud se refiere a un número definido de comunicaciones electrónicas, producidas entre el Subsecretario del Interior y la Gobernadora de Melipilla; la petición no es indeterminada, sino específica. Está acotada en el tiempo, por la materia y por la cantidad de correos que guardan relación con al asunto. El requerimiento de información no se extiende a toda la correspondencia digital realizada entre el Subsecretario y la Gobernadora, sino sólo a la que tenga relevancia pública referida a los fondos del Programa Manos a la Obra en lo relativo a la reconstrucción en la Comuna de Melipilla. Para cumplir con lo requerido bastaba con que el Subsecretario hubiera hecho una selección de la información según ese criterio, siguiendo los principios de la divisibilidad y de máxima divulgación (artículo 11 de la Ley $\mathrm{N}^{\circ} 20.285$ ) y, en caso de disconformidad por parte del Alcalde de Melipilla, entonces éste podría haber recurrido ante el CPLT poniendo en marcha el procedimiento de reclamo establecido por la propia Ley $\mathrm{N}^{\circ} 20.285$;

b.- Porque el principio de divisibilidad tiene la virtud de generar una especie de óptimo paretiano que busca garantizar la máxima efectividad de los derechos y bienes jurídicos involucrados;

c.- Porque esta ponderación, siguiendo lo dispuesto en la Ley $\mathrm{N}^{0} 20.285$, excluye cualquier referencia al soporte o formato de la información solicitada, como son los correos electrónicos. Lo que interesa es la naturaleza de la información misma, no su formato. En un ejercicio de ponderación entre el derecho al respeto y protección de la vida privada, artículo $19 \mathrm{~N}^{\circ} 4$, frente al derecho a la información del artículo $19 \mathrm{~N}^{\mathrm{0}} 12$ de la Constitución, no cabe apelar a una consideración abstracta en que siempre la primacía la tenga el resguardo de la privacidad. Tal posición, que acepta la tesis de la jerarquía entre derechos, se aleja de la determinación fáctica del caso concreto, siendo contraria a la naturaleza del recurso de inaplicabilidad y no es coherente con la jurisprudencia de esta Magistratura;

d.- Que la autorización mediante decreto supremo por parte del Ministerio del Interior para utilizar correos electrónicos en este programa público, exige un juicio de ponderación, puesto que, de asumir lo contrario, jamás podría existir una decisión pública adoptada por un correo electrónico que pudiera ser conocida, con lo cual se vulneraría la Constitución. Los acuerdos y contratos para la entrega de materiales a todas las municipalidades del país afectadas por el terremoto incorporaron, como procedimiento y como respaldo de una decisión pública, el uso de los correos electrónicos. ¿Por qué, entonces, una solicitud del Alcalde de Melipilla que intenta conocer sobre lo que aconteció con 
recursos que estima adeudados a su comuna, no puede recurrir a esa vía para indagar por qué no se le reembolsaron los gastos efectuados?;

34.-Que, a nuestro entender, la forma de dilucidar el aparente conflicto a que se ha aludido, consiste en diferenciar el tipo de información vertida en los correos electrónicos, toda vez que ellos pueden encerrar tanto información pública, como son los antecedentes solicitados en el asunto de fondo, en los términos del citado artículo $8^{\circ}$ de la Constitución, cuanto noticias u opiniones de carácter meramente personal o pareceres y sugerencias para la aprobación de una resolución, que estarían cubiertos por el así denominado "privilegio deliberativo", a que alude el literal b) del artículo 21 de la Ley $\mathrm{N}^{\circ}$ 20.285;

35.-Que, puestas así las cosas, queda de manifiesto que lo relevante para decidir acerca de la publicidad o reserva de la información de que se trate, es su contenido, es decir, la naturaleza de los datos que ella comprende, y no el medio material que le sirve de soporte o formato, en este caso, un correo electrónico emanado de las cuentas institucionales de las autoridades concernidas;

36.- Que, por lo mismo, no toda información envuelta en un correo electrónico personal es necesariamente reservada o confidencial, como tampoco es forzosamente pública toda información transmitida desde una casilla de correos de una entidad pública. Este es también el parecer que ha primado en la legislación comparada y en las decisiones de los tribunales internacionales, como queda de manifiesto en los informes en derecho de Ignacio Covarrubias y José Manuel Díaz de Valdés, por una parte, y de Tomás Vial, por otra, acompañados a estos autos;

\section{$(\ldots)$}

43.- Que, por todo lo razonado precedentemente, estos disidentes nos pronunciamos por el rechazo del presente requerimiento de inaplicabilidad.

Redactó la sentencia el Ministro señor Carlos Carmona Santander y la disidencia el Ministro señor Gonzalo García Pino.

Comuníquese, notifíquese, regístrese y archívese.

Rol No 2153-11-INA.

\section{COMENTARIO}

En un anterior comentario jurisprudencial observé que la forma en que los tribunales presentan jurídicamente la contienda en discusión, particularmente respecto de las categorías jurídicas dentro de las cuales subsumen una disputa, es un acto que constituye realidades $^{1}$; incluso sería posible sostener que dicha elección determina en gran medida

${ }^{1}$ Fernando Muñoz León, “ANEF con SII: ¿Libertad sindical, debido proceso o libertades públicas?”, Ius et Praxis, Vol.17 No 2 (2011), 537-550. 
el resultado mismo de la contienda. Es por esto que la caracterización jurídica de una disputa reviste en sí misma una gran importancia; y así, tal como una adecuada caracterización puede reportar grandes ventajas desde el punto de vista de la sistematicidad y coherencia del sistema jurídico, una mala caracterización puede significar desde una oportunidad perdida hasta un traspié con graves consecuencias.

Esto es, a mi juicio, lo que ha ocurrido en la sentencia redactada por el Ministro Carlos Carmona mediante la cual el Tribunal Constitucional intervino en la discusión sobre la publicidad o privacidad de los correos electrónicos de autoridades públicas; más específicamente, del Ministro Secretario General de la Presidencia y del Subsecretario del Interior. Esta discusión, en mi opinión, debiera haber girado en torno a los alcances del artículo $21 \mathrm{~N}^{\circ}$ 1, letra b) de la Ley de Transparencia, que establece la reserva de los "antecedentes o deliberaciones previas a la adopción de una resolución, medida o política, sin perjuicio que los fundamentos de aquellas sean públicos una vez que sean adoptadas”. En lugar de ello, el Ejecutivo lo planteó como un asunto de derechos fundamentales -esto es, como una discusión sobre el respeto y protección a la vida privada y la inviolabilidad de toda forma de comunicación privada-, tesis que el Tribunal Constitucional acogió en la sentencia en comento.

Presentar así el asunto ofrecía dos ventajas para el Ejecutivo. La primera es que ello ofrecía un lenguaje de principios, valórico, muy superior "comunicacionalmente" a los términos del artículo $21 \mathrm{~N}^{\circ} 1$, letra b), que parecen invitar a que cualquier entrevistador le pregunte al Subsecretario por qué si cierta decisión es pública se ocultan las deliberaciones que condujeron a su adopción. La segunda, muy relacionada con la anterior, es que esta parece constituir una estrategia judicial "ganadora", debido a la vocación expansiva de los derechos fundamentales. Uno incluso podría sostener que el Ejecutivo estaba simplemente equiparando sus armas con las de aquellos que sostienen que nuestro sistema constitucional contiene un derecho fundamental de acceso a la información ${ }^{2}$.

El Ejecutivo, en efecto, ha ganado. El Tribunal Constitucional ha adoptado la tesis de los derechos fundamentales y, en consecuencia, ha declarado inaplicable el artículo 5 inciso $2^{\circ}$ de la Ley de Transparencia -que establece que "es pública la información elaborada con presupuesto público y toda otra información que obre en poder de los órganos de la Administración, cualquiera sea su formato, soporte, fecha de creación, origen, clasificación o procesamiento, a menos que esté sujeta a las excepciones señaladas"- para los recursos de ilegalidad promovidos ante la Corte de Apelaciones de Santiago por el Ministro Secretario General de la Presidencia y por el Subsecretario del Interior contra las resoluciones del Consejo para la Transparencia que les obligaban a hacer públicos los correos electrónicos en disputa. Así lo ha resuelto ya en la sentencia Causa Rol No 2153-2011, aquí en comento, y así lo hará próximamente en la Causa Rol $\mathrm{N}^{\circ}$ 2246-12, ya alegada a la fecha y respecto de la cual el Tribunal ya ha anunciado a las partes que acogerá también la inaplicabilidad. En consecuencia la Corte de Apelaciones

${ }^{2}$ Gonzalo García Pino y Pablo Contreras Vásquez, "Derecho de acceso a la información en Chile: nueva regulación económica e implicancias para el sector de la defensa nacional”, Estudios Constitucionales, Vol. 7 No 1 (2009), 137-175. 
de Santiago, al revisar la decisión del Consejo para la Transparencia de ordenar la entrega de los correos electrónicos en cuestión, no podrá aplicar la disposición transcrita.

Pero la ganancia del Ejecutivo es una pérdida para el sistema en su conjunto; el que obtuvo un pronunciamiento jurisprudencial que, además de ser innecesariamente expansivo, desperdicia la oportunidad de generar reglas claras en un proceso de alto impacto público sobre la aplicación del artículo $21 \mathrm{~N}^{\circ} 1$, letra b) de la Ley de Transparencia. A nuestro sistema jurídico le conviene contar con claridad respecto de cuándo los funcionarios públicos pueden invocar dicha causal para retener información y cuándo no. El Ministro Carmona estuvo a punto de lograrlo en el considerando $19^{\circ}$ de esta sentencia, al observar que los órganos llamados a tomar decisiones "deben tener un margen para explorar alternativas con libertad, sin tener que saber que sus opiniones se harán públicas”. Lamentablemente, esta reflexión se pierde en un mar de consideraciones inconducentes. Esto es un problema, puesto que los tribunales no han generado reflexiones significativas sobre este punto; según el buscador de jurisprudencia del Consejo para la Transparencia, existe bastante jurisprudencia administrativa del Consejo para la Transparencia, poca de las Cortes de Apelaciones, y nada de la Corte Suprema. El Tribunal Constitucional, por su parte, ya se había pronunciado sobre el artículo $21 \mathrm{~N}^{\circ} 1$, letra b) en su sentencia en la Causa Rol No 1990-2011, declarándolo allí inaplicable en la parte que señala "sin perjuicio que los fundamentos de aquellas sean públicos una vez sean adoptadas", puesto que a su juicio tal disposición afectaba la vida privada del profesional recurrente como consecuencia de que facultaba al Consejo para la Transparencia para disponer la exhibición de evaluaciones personales. En lugar de elaborar una interpretación razonable sobre la reserva de las deliberaciones conducentes a la toma de decisiones, el Tribunal ha optado por declarar inaplicable su operación actual.

Esta última resolución, sumada a las dos identificadas en este comentario, permiten a estas alturas hablar de una predilección del Tribunal Constitucional por la privacidad por sobre la publicidad, con todo el simbolismo que ello representa. Para el Tribunal Constitucional, en esta materia lo privado está por sobre lo público, tal como ocurre también en otras áreas de nuestro derecho constitucional; piénsese en el ámbito económico, donde también nuestra jurisprudencia y nuestra doctrina, invocando la particular concepción que se tiene en nuestro país sobre el principio de subsidiariedad, hacen primar los intereses privados por sobre el interés público de contar con una regulación vigorosa orientada a la justicia social y el bien común. Con todo ello el genuino centro de nuestro derecho constitucional, la afirmación de que "Chile es una república democrática" contenida en el artículo $4^{\circ}$ del texto constitucional, se pierde cada vez más entre la neblina.

Volviendo a la sentencia en comento, habría que agregar que además de desperdiciar la oportunidad de generar una reflexión jurisprudencial sobre la causal de reserva del artículo $21 \mathrm{~N}^{\circ}$ 1, letra b), la sentencia comete el pecado argumentativo de discutir con una posición que nadie sostiene. En efecto, como comprobará el lector, ella dedica varios párrafos a defender la evidente pero irrelevante postura de que "los funcionarios públicos tienen derechos constitucionales". Desde luego que los tienen; y, por cierto, nadie lo ha puesto en duda. La discusión, que el voto de minoría sí acomete, es cómo conjugar dichos derechos fundamentales con el interés público por acceder a la información solicitada en el caso de autos. El Tribunal Constitucional solo puede plantear el 
asunto en los altisonantes términos escogidos por el Ejecutivo ignorando el principio de la divisibilidad, consagrado en el artículo 11, letra b) de la Ley de Transparencia, y según el cual "si un acto administrativo contiene información que puede ser conocida e información que debe denegarse en virtud de causa legal, se dará acceso a la primera y no a la segunda". Para mayor claridad: si los correos electrónicos de marras contuvieran información efectivamente relacionada con la vida privada del Ministro o del Subsecretario, el Consejo para la Transparencia podría tarjar dicha información de la copia impresa entregada a los solicitantes, o de una forma análoga si se tratara de copias digitales.

Otra divagación innecesaria por su irrelevancia en que incurre el Tribunal consiste en afirmar que "el mandato de publicidad no es absoluto". Ningún mandato jurídico, como es sabido en esta época de ponderaciones, exámenes de proporcionalidad y balancing tests, es absoluto. La pregunta importante, en este caso, es en virtud de qué consideraciones algo es hecho público o no. Tal pregunta no puede ser respondida a brochazos - "los funcionarios públicos tienen derechos constitucionales"-, sino que ha de ser respondida con un pincel fino, que permita hacer distinciones y establecer matices, como hace el voto disidente en sus considerandos $20^{\circ}$ a $36^{\circ}$. Tampoco puede ser respondida mediante argumentos fácticos, tales como lo hace el Tribunal al observar en su considerando $19^{\circ}$ que "hay conversaciones, reuniones, llamados telefónicos, diálogos, órdenes verbales, entre los funcionarios, de los cuales no se lleva registro de ningún tipo” y que, por ello, "nunca serán públicos”. ¿Qué tal si se estableciera la obligación de grabar todas las conversaciones de las autoridades públicas sobre asuntos propios de su cargo? Si bien esto podría ser poco conveniente presupuestariamente, tal problema no constituiría una objeción jurídica al eventual establecimiento de tal obligación.

También resulta difícil comprender por qué el Tribunal considera necesario defender la tesis de que "los correos electrónicos no son necesariamente actos administrativos". Dar por probada esta afirmación es bastante irrelevante, pues la pretensión de hacer públicos los correos de las autoridades no se funda jurídicamente en que ellos constituyan actos administrativos, sino en que ellos contienen deliberaciones previas a la adopción de una resolución, medida o política", consisten en un soporte elaborado "con presupuesto público" y corresponden a información que obra "en poder de los órganos de la Administración". Por cierto, en ese sentido es valorable que el Tribunal proclame que la Constitución "debe interpretarse a la luz del progreso tecnológico”. El problema es que parece no haber sacado la conclusión adecuada de dicha premisa; esto es, que debido a la importancia que en una era de progreso tecnológico y de gobierno electrónico, los correos electrónicos pasan a ser un importante medio de comunicación cuyo escrutinio no debe ser evitado a priori afirmando que "los funcionarios públicos tienen derechos constitucionales".

Por último, cabe consignar como curiosidad que el Ministro Carmona aprovecha esta sentencia para hacer eco, en el considerando $8^{\circ}$ del texto, del "nativismo jurídico" del Justice Antonin Scalia. La crítica de este a la invocación de jurisprudencia extranjera se hizo famosa mediante sus disidencias en Lawrence $v$. Texas ${ }^{3}$, donde afirma que "las

\footnotetext{
${ }^{3}$ Lawrence v. Texas, 539 U.S. 558 (2003).
} 
titularidades constitucionales" no nacen "porque las naciones extranjeras despenalicen una conducta" y que la discusión judicial de "aquellos puntos de vista extranjeros" es "en consecuencia comentario (dicta) sin importancia"; y en Roper v. Simmons ${ }^{4}$, donde lamentó amargamente que en virtud del voto de mayoría de dicha sentencia "los puntos de vista de otros países y de la así llamada comunidad internacional se han tomado el centro del escenario", y declarando que "la premisa básica del argumento de la Corte -esto es, que el derecho norteamericano debe adecuarse al derecho del resto del mundo- debe ser rechazada de plano". Así, el Ministro Carmona nos recuerda que "la decisión que se adopte, ha de basarse en nuestro marco constitucional”, y que si "avanzamos o retrocedemos o permanecemos igual respecto de lo que sucede en otros países, en la materia debatida" no es algo que le toque examinar al Tribunal Constitucional, pues si juzgara "en base al estándar de lo que los otros países puedan considerar jurídicamente correcto, dejamos de ser un órgano encargado de velar por la supremacía de nuestra Constitución”.

¿Qué lleva al Ministro Carmona a hacer esta afirmación, que en otras circunstancias habría sido irrelevante de tan obvia que es? ¿Qué hay implícito en ella?; ¿cuál es el argumento al cual ella, callándolo, intenta responder? Una posible respuesta es que, en este caso, el contraste con situaciones similares de otros países dejaría en muy mala posición a la decisión adoptada por el Tribunal Constitucional. Piénsese por ejemplo, sin ir más lejos, en la jurisprudencia de la Corte Suprema norteamericana, que en 1974 ordenó al Presidente Richard Nixon entregar al Juez del Distrito de Columbia John Joseph Sirica las cintas con grabaciones de conversaciones sostenidas por él en diversas localizaciones de la Casa Blanca, en el marco de la investigación judicial sobre el caso Watergate ${ }^{5}$. A la luz de este tipo de precedentes, se entiende que el estado de Alaska no haya puesto reparos a la entrega de miles de páginas de correos electrónicos enviados y recibidos por la Gobernadora Sarah Palin durante su ejercicio del cargo ${ }^{6}$. En cambio, de haber hecho aplicables a estos casos el criterio expuesto por nuestro Tribunal Constitucional en la sentencia en cuestión, tanto la entrega de las cintas de Nixon como de los correos electrónicos de Palin habría sido imposible. Nice going, pal!

\footnotetext{
${ }^{4}$ Roper v. Simmons, 543 U.S. 551 (2005).

${ }^{5}$ United States v. Nixon, 418 U.S. 683 (1974).

${ }^{6}$ Véase http://projects.nytimes.com/palin-emails/.
} 
